\title{
La monitorización y simulación: herramientas para la mejora de la preservación, confort y ahorro energético de espacios patrimoniales
}

\author{
Carmen María Muñoz González | grupo de investigación TEP130, Universidad de Sevilla \\ Ángel L. León Rodríguez, Jaime Navarro Casa | Dpto. Construcciones Arquitectónicas I, ETSA, Universidad de Sevilla \\ URL de la contribución <www.iaph.es/revistaph/index.php/revistaph/article/view/3651>
}

La tierra está cambiando con mayor velocidad que nunca, el calentamiento global del mundo ya no es un concepto tan lejano, sino una amenaza real en el futuro del hombre. Así pues, el sector de la edificación debe reconocer sus responsabilidades e influencia en el calentamiento global y en la preservación de los valiosos recursos energéticos, ya que es uno de los principales emisores de $\mathrm{CO}_{2}$ en el planeta.

Dentro de este sector, los edificios patrimoniales en general son los menos eficientes debido principalmente al gran volumen que presentan y a su inercia térmica. Igualmente las normas de construcción aplicadas a estos edificios fueron diferentes de las existentes hoy en día. Estas edificaciones no satisfacen en su mayoría las necesidades de preservación, confort humano y eficiencia energética. Así pues para tratar estas cuestiones debemos cambiar la manera de rehabilitar estos edificios existentes de modo que reduzcamos los impactos negativos en el medio ambiente (POLO LÓPEZ; FRONTINI; FRIESEN et ál., 2014).

En este momento nos encontramos en un contexto en el que Europa puede aplicar o no unos requisitos mínimos en estos edificios pero, por otro lado, la normativa pide que estos edificios sean un ejemplo cuando se usan para la administraciones públicas, ya que se han visto sometidos a una intervención de cambio de uso. No obstante, hoy por hoy existe un amplio número de edificios patrimoniales en toda Europa que no han cambiado su uso o incluso son de propiedad privada. Por lo tanto, este sector de la edificación queda exento de tener que cumplir cierto requerimiento energético y las directivas europeas de eficiencia energética dejan al margen estos inmuebles. Sin embargo, la mayoría de expertos en el ámbito patrimonial tienen la opinión de que estos inmuebles no pueden quedar fuera de la adecuación energética.

Por otro lado, existe un gran vacío de referencias en cuanto a normativa en este campo. Esto ha ocasionado que expertos en la materia elaboren ciertos instrumentos específicos como las cartas de Restauro (CARTA ATENAS, 1931), para la rehabilitación o intervención en el patrimonio inmueble (estas han sido elaboradas según la experiencia adquirida durante años de trabajo). Estas cartas a veces dificultan la rehabilitación energética de los edificios patrimoniales debido a que no se puede realizar actuaciones en la envolvente del edificio o no se puede emplear materiales que no sean tradicionales, etc. (CARTA VENECIA, 1964; CARTA CRACOVIA, 2000). La envolvente del edificio desempeña un papel fundamental en garantizar un buen nivel de aislamiento térmico y, al no poder actuar sobre ella, las intervenciones en estos edificios se enfocan a la aplicación de técnicas ambientales activas para encontrar un equilibrio y satisfacer los requisitos de la construcción, los objetos expuestos y sus ocupantes.

Con el fin de hacer frente a estos retos es necesario desarrollar una metodología que pueda identificar el modo más adecuado de hacer este sector eficiente, al mismo tiempo que respete su valor patrimonial. Los criterios actuales, tanto para aplicar técnicas ambientales como para ver cómo funcionan, están enfocados fundamentalmente a edificios de nueva construcción. Así pues, la mayor dificultad que se nos presenta para mejo- 

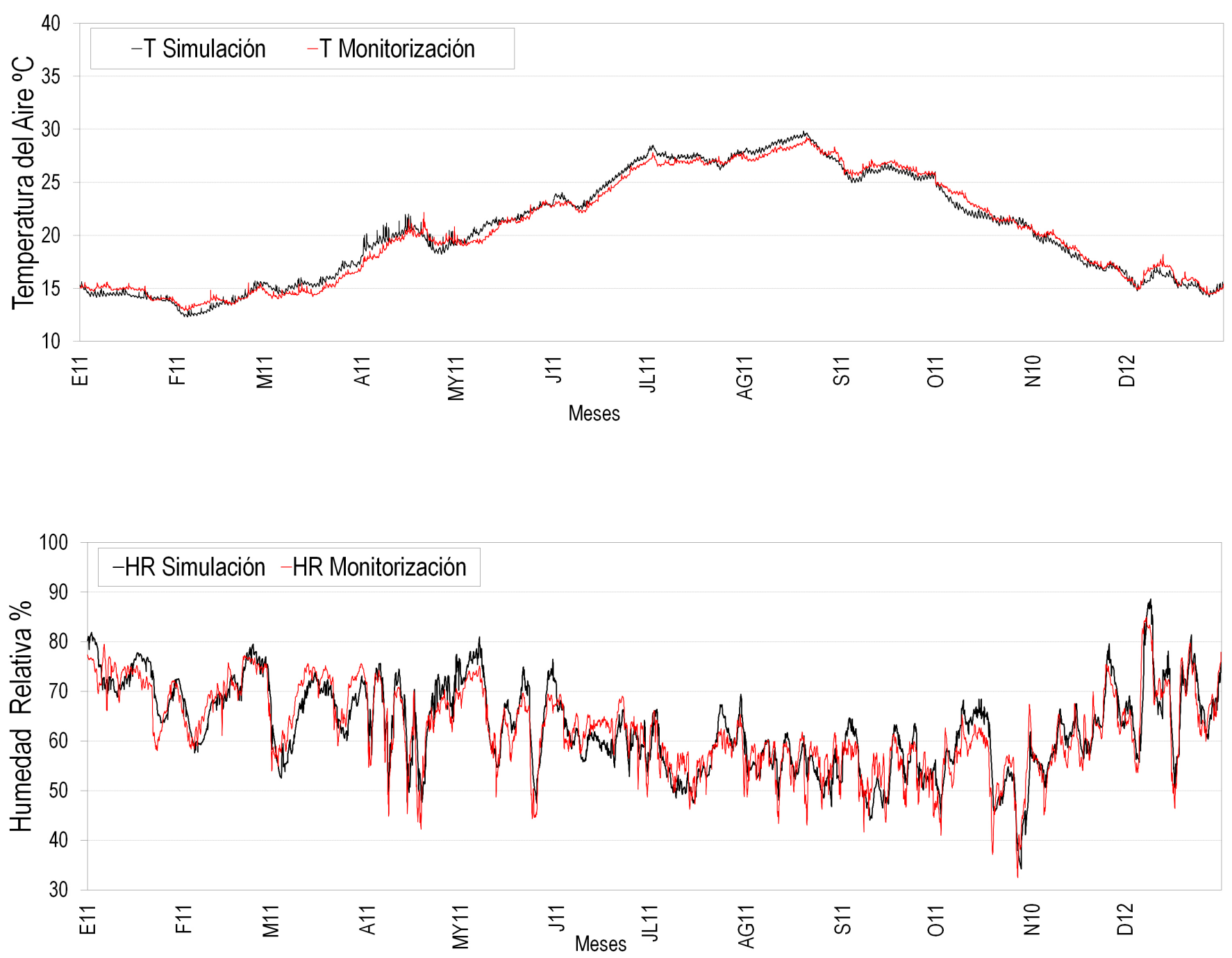

Validación de parámetros ambientales del interior de una de las iglesias de estudio | gráficos elaboración propia

rar el comportamiento energético de estos inmuebles es tener un conocimiento profundo de su comportamiento real.

Los técnicos disponemos de nuevas herramientas que permiten estimar con precisión las condiciones ambientales de un espacio. Estas nuevas herramientas, disponibles a partir de la informática, ayudan a los expertos a diseñar y evaluar los diferentes sistemas teniendo un conocimiento previo a la intervención (HUIJBREGTS; KRAMER; SCHIJNDEL et ál., 2011). No obstante, la aplicación de estos programas de cálculo en edificios patrimoniales no está siendo muy acertada en sus resultados, pues su uso está pensado para edificios contemporáneos. Igualmente desde un punto de vista técnico, estos programas de simulación son bastante opacos en los criterios de cálculo empleados y a veces su uso resulta complejo. 
_a debate La eficiencia energética y la edificación histórica | coordinan Mónica López Sánchez, Ana Yáñez Vega

Así pues el grupo de investigación TEP 130 Arquitectura, patrimonio y sostenibilidad de la Universidad de Sevilla, en colaboración con el Instituto Universitario de Arquitectura y Ciencias de la Construcción, ha desarrollado una metodología de investigación para analizar las mejoras de las condiciones ambientales y su eficiencia energética en patrimonio cultural inmueble, centrando su investigación en el estudio de una serie de casos reales. A través de la monitorización de estos edificios patrimoniales reales y la utilización de herramientas informáticas de simulación, se estudia la optimización de la demanda energética en los edificios patrimoniales cumpliendo con los requerimientos de preservación y confort térmico.

La investigación estaba comprendida en varia fases de estudio. En la primera fase se requirió de un conocimiento mínimo de las características arquitectónicas, constructivas y patrimoniales de los edificios de estudio. A continuación se llevó a cabo la monitorización de los edificios, de manera que se pudiera realizar un diagnóstico de la situación real. En una segunda fase se generaron modelos informáticos a partir de la información obtenida de la monitorización y de las mediciones in situ. En esta fase se validaron los modelos de simulación, aunque uno de los principales problemas con los que nos encontramos fue determinar las capas que componían los cerramientos y la transmitancia de los materiales tradicionales. Para ello recurrimos al uso de la termografía determinando así la homogeneidad de la envolvente y al uso de las mediciones in situ para determinar la cantidad de energía que conducían los elementos constructivos.

Una vez validado el modelo de simulación, se ensayaron una serie de intervenciones sobre estos edificios basadas en la aplicación de técnicas ambientales pasivas y activas. Finalmente se realizó un análisis crítico y comparativo de las diferentes propuestas concluyendo cuales de ellas eran más transcendentales desde el punto de vista de la eficiencia energética, la preservación del patrimonio y el confort humano.

\section{BIBLIOGRAFÍA}

- CARTA de ATENAS. Conferencia de Atenas (1931). En UNESCO Cultural Heritage Laws Database [en línea]. <http://www.unesco.org/culture/natlaws/media/pdf/guatemala/ guatemala_carta_de_atenas_1931_spa_orof.pdf> [Consulta: 09/07/2015]

- CARTA de VENECIA. Carta internacional sobre la conservación y la restauración de monumentos y de conjuntos histórico-artísticos (1964). En UNESCO Cultural Heritage Laws Database [en línea]. <http://www.unesco.org/culture/natlaws/ media/pdf/guatemala/guatemala_carta_venecia_1964_spa_ orof.pdf> [Consulta: 09/07/2015]

- CARTA de CRACOVIA. Principios para la conservación y restauración del patrimonio construido (2000). En UNESCO Cultural Heritage Laws Database [en línea]. <http://www. unesco.org/culture/natlaws/media/pdf/guatemala/guatemala_ carta_cracovia_2000_spa_orof.pdf> [Consulta: 09/07/2015]

- HUIJBREGTS, Z.; KRAMER, R.P.; SCHIJNDEL, A. W. M. VAN et ál. (2011) Computational $m$ odelling of the impact of climate change on the indoor environment of a historic building in the Netherlands. 9th Nordic symposium on Building Physics, The Netherlands, 2011

- POLO LÓPEZ, C. S.; FRONTINI, F.; FRIESEN, G. et ál. (2013) Energy efficiency and renewable solar energy integration in heritage historic buildings. Energy Procedia, n. ${ }^{\circ} 48,2013$, pp. 1493-1502 